\title{
Progress Towards Interruption of Transmission of Chagas Disease
}

\author{
Alvaro Moncayo \\ World Health Organization, TDR, CH-1211, Geneva 27, Switzerland \\ Key words: Chagas disease - transmission - Trypanosoma cruzi
}

Chagas disease, named after the Brazilian physician Carlos Chagas who first described it in 1909, exists only on the American Continent. It is caused by a flagellate protozoan parasite, Trypanosoma cruzi, transmitted to humans by triatomine insects. The geographical distribution extends from Mexico to the south of Argentina. The disease affects 1618 million people and some 120 million, i.e. about $25 \%$ of the population of Latin America is at risk of acquiring Chagas disease.

There are two stages of the human disease: the acute stage which appears shortly after the infection and the chronic stage which appears after a silent period that may last several years. The lesions of the chronic phase irreversibly affect the autonomous nervous tissues of internal organs namely the heart, oesophagus and colon and the peripheral nervous system. After several years of an asymptomatic period, $27 \%$ of those infected develop cardiac lesions which may lead to sudden death, $6 \%$ develop digestive damage mainly megaviscera, and 3\% will present peripheral nervous involvement.

The risk of infection with Chagas disease is directly related to poverty: the blood-sucking triatomine bug which transmits the parasite finds a favourable habitat in crevices in the walls and roofs of poor houses in rural areas and in the peripheral urban slums. The rural/urban migration movements that occurred in Latin America in the 70's and 80's changed the traditional epidemiological pattern of Chagas disease and transformed it into an urban infection that can be transmitted by blood.

The strategy for the interruption of vectorial and transfusional transmission of this disease is aimed at the prevention of new cases in children and young adults. The interruption of vectorial transmission is made through spraying the infested houses with insecticides. The interruption of trans-

Fax: +41-22-791.4774. E-mail: moncayoa@who.ch Received 9 June 1999

Accepted 9 August 1999 fusional transmission is achieved by screening blood samples in blood banks using serological techniques and discarding the infected ones.

INITIATIVE OF THE SOUTHERN CONE COUNTRIES (ARGENTINA, BOLIVIA, BRAZIL, CHILE, PARAGUAY, PERU AND URUGUAY)

In these countries there are 11 millions of infected persons and 50 millions are at risk.

Chagas disease is recognized as an important public health problem and is given increasing priority for control, as demonstrated by the above government initiative which is very successful and is paying high dividends. By cutting the transmission of this disease in the countries of the Southern Cone the incidence of Chagas disease will be reduced by over $70 \%$.

A total of US\$ 303 million has been allotted from national sources of the six countries for control operations since the start of the initiative in 1991. With this investment, it is estimated that in the next ten years the economic loss due to Chagas disease will be reduced by US\$12,000 million which is equivalent to a return of US\$ 45.2 per each US dollars invested in the elimination of transmission.

Current data on house disinsectation, serology in children and young adults and coverage of blood banks screening indicate that the vectorial and transfusional transmission of Chagas disease will be interrupted in the following countries in the coming years: Uruguay (1997), Chile (1999), Argentina and Brazil (2001), Bolivia and Paraguay (2003) (Table, Figs 1, 2) (WHO 1994, 1995, 1996, 1997, 1998a, 1999, PAHO 1998).

Control activities are progressing as scheduled in Bolivia but at this stage there are no entomological or epidemiological data available to assess the impact of the control programmes in this country and to estimate a date for achievement of interruption of transmission. These data should be available in 2001, after four to five years of continued control activities and completion of crosssectional entomological and serological surveys. Peru joined in March 1997 as the southern departments of this country are also infested by Triatoma 
TABLE 1

Human infection by Trypanosoma cruzi and reduction of incidence. Southern Cone Initiative, 1983-1997

\begin{tabular}{lcccc}
\hline Country & $\begin{array}{c}\text { Age group } \\
\text { (years) }\end{array}$ & $\begin{array}{c}\text { Infection in 1983 } \\
\text { (Rates x 100) }\end{array}$ & $\begin{array}{c}\text { Infection in 1997 } \\
\text { (Rates x 100) }\end{array}$ & $\begin{array}{c}\text { Reduction of } \\
\text { incidence (\%) }\end{array}$ \\
\hline Argentina & 18 & 4.5 & 1.2 & 85 \\
Brazil & $7-14$ & 18.5 & 0.17 & 96 \\
Bolivia & $1-4$ & 33.9 & ND & ND \\
Chile & $0-10$ & 5.4 & 1.2 & 81.2 \\
Paraguay & 18 & 9.3 & 3.9 & 60 \\
Uruguay & $6-12$ & 2.5 & 0.06 & 99 \\
\hline
\end{tabular}

Southern Cone Initiative

Elimination of transmission: Incidence of infection 1980-97

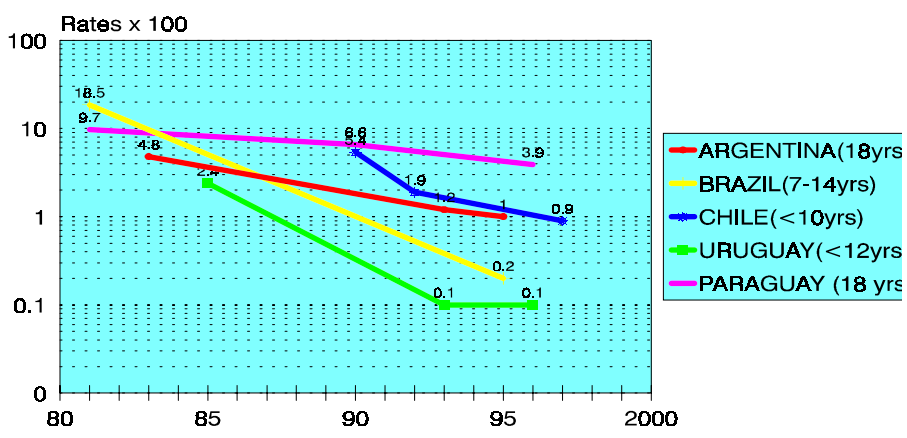

Source: Reports by National Chagas disease control programmes, 1993-98

Southern Cone Initiative

Elimination of transmission: house infestation by triatomines 1982-97

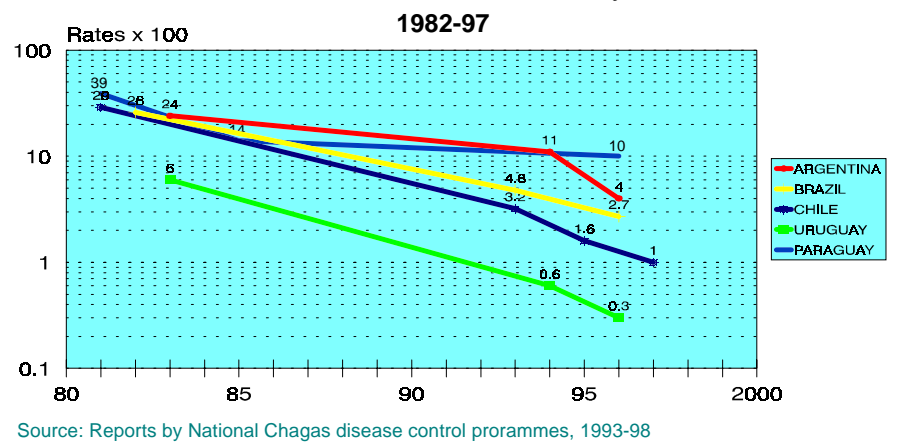

infestans.

Uruguay was declared free of vectorial and transfusional transmission of Chagas disease by an International Commission in September 1997 (WHO 19998a), Chile will accomplish the interruption goals at the end of 1999 (WHO 1999).

\section{INITIATIVE OF THE ANDEAN COUNTRIES AND THE CENTRAL AMERICAN COUNTRIES}

In these countries there are 5-6 million infected individuals and 25 million are at risk of contracting the infection.

As the vectors of Chagas disease in these countries are not strictly domiciliated, it is necessary to adapt and test the successful vector control strate- gies against the domiciliated triatomines to the local entomological conditions.

In the Andean countries of Colombia, Ecuador, Peru, Venezuela, progress in blood banks control is proceeding well and all of them have issued legislation in this respect. The elimination of the vectorial transmission was launched at an intergorvernment meeting held in Bogotá in February 1997 where detailed country by country plans of action including annual goals, budgetary needs, evaluation mechanisms and research needs were prepared.

In the central American countries, Costa Rica, El Salvador, Guatemala, Honduras, Mexico, Nicaragua, and Panama, progress in blood banks con- 
trol is also proceeding well and all of them except one have issued legislation for compulsory blood screening against blood infected by T. cruzi. Similarly, the elimination of the vectorial transmission was launched at an intergorvernment meeting held in Tegucigalpa in October 1997 where detailed country by country plans of action including annual goals, budgetary needs, evaluation mechanisms and research needs were prepared.

\section{MEDICAL COSTS VS PREVENTION COSTS}

According to the UNDP Human Development Report (1996), the estimated average annual percapita gross domestic product in Latin America, is US\$2,966. Thus, the economic loss for the Continent due to early mortality and disability by this disease in economically most productive young adults, currently amounts to US\$18,000 million which is equivalent to $5 \%$ of the external debt of the whole Continent in 1995.

The direct costs due to ambulatory medical care per patient per year in the countries of the Southern Cone Initiative are estimated as follows: Argentina US\$ 406; Brazil 1,250; Bolivia 227 and Uruguay 877. The weighted average cost for the six countries is US\$ 559/patient/year (PAHO 1997). The total annual expenditure due to ambulatory medical care in the six countries of the Southern Cone Initiative amounts to a total of US\$ 2, 238 million while the annual expenses for vector and blood banks control to interrupt transmission of Chagas disease in the same countries is US\$ 37 million. In other words for each US dollar invested in prevention of new cases of Chagas disease there is a saving of US\$ 37 in medical expenses every year. Recent figures from Brazil indicate that for each dollar invested in prevention US\$17.50 are saved in medical costs (Akhavan 1997).

In the Andean countries the economic costs of acute and chronic cases of Chagas disease, including costs of treatment, cardiac pacemakers and economically productive years lost in 1996 amount every year to US\$ 391 millions. The cost of elimination of transmission in these countries will be US\$ 16 millions per year from 1998-2005 which represents an annual return of US\$24 of savings in medical costs for each dollar invested in prevention (WHO 1997b).

In Honduras, one of the countries of the Central American Initiative, the medical costs for implantation of pacemakers in current chronic cardiac patients are estimated in US\$ 375 millions. The costs for the interruption of transmission from 1997 to 2005 amount to US\$ 11 millions which represents a return of US\$ 34 for each dollar invested in prevention of new cases who will need the pacemaker in 10 to 15 years (WHO 1997c).
THE TIME TABLE TOWARDS INTERRUPTION OF TRANSMISSION

1980-1985: prevalence cross-sectional studies on human infection and house infestation in nine countries are carried out

1980-1985: standardization of serological techniques and creation of a continental network of reference laboratories

1984-1990: follow-up prospective studies on the course of human infection

1987-1989: cloning of parasite genome and production of defined antigens for improvement of diagnostic techniques

1990: industrial production of kits for blood banks control in Argentina

1988-1992: development of new tools for vector control

1988-1993: multi country field studies for evaluation of new vector control tools

1992: industrial production of paints, canisters and sensor boxes in Argentina and Brazil

1991: initiative of the Southern Cone countries is launched

1997: initiatives of the Andean countries and the Central American countries are launched

1997: Uruguay declared free of vectorial and transfusional transmission of Chagas disease

1998: the 51st World Health Assembly endorses the goal for elimination of transmission of Chagas disease on the American continent in 2005 (WHO 1998b).

\section{REFERENCES}

Akhavan D 1997. Analysis of cost-effectiveness of the Chagas disease control programme, Ministry of Health, National Health Foundation, Brasília.

PAHO 1997. Pan American Health Organization, Report of the VI Meeting of the Intergovernment Commission of the Southern Cone Initiative, Santiago, Chile.

PAHO 1998. Pan American Health Organization, Report of the VII Meeting of the Southern Cone Initiative, Buenos Aires.

UNDP 1996. UNDP Human Development Report 1996, Oxford University Press, New York, 211 pp.

World Health Organization 1994. Weekly Epidemiol Record 6: 38-40.

World Health Organization 1995. Weekly Epidemiol Record 3: 13-16.

World Health Organization 1996. Weekly Epidemiol Record 2: 12-15.

World Health Organization 1997a. Weekly Epidemiol Record 1: 1/2-1. 
WHO 1997b. World Health Organization, Division of Control of Tropical Diseases, Elimination of Chagas disease as a Public Health Problem, Projected costs 1997-2010, Geneva, CTD/TRY/97.14 p. 27.

WHO 1997c. World Health Organization, Division of Control of Tropical diseases, Elimination of Chagas disease as a Public Health Problem, Projected costs
1997-2010, Geneva, CTD/TRY/97.14 p. 41. World Health Organization 1998. Weekly Epidemiol Record 1: 1/2-1.

WHO 1998b. World Health Assembly, Resolution WHA.51.14.

World Health Organization 1999. Weekly Epidemiol Record 2: 9-16. 